UN HECHO PRETÉRITO: LA INSTAURACIÓN DE LAS ZONAS ECONÓMICAS ESPECIALES EN MÉXICO.

\title{
UN HECHO PRETÉRITO: LA INSTAURACIÓN DE LAS ZONAS ECONÓMICAS ESPECIALES EN MÉXICO
}

\section{A PRETERITE FACT: THE INSTAURATION OF SPECIAL ECONOMIC AREAS IN MEXICO}

Mijael Altamirano Santiago*

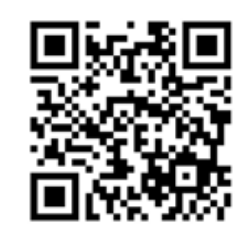

*Doctor en Ciencias Políticas y Sociología. Profesor investigador en el CIECAS-IPN. ORCID: https://orcid.org/0000-0001-5194-2944.

Dirección para recibir correspondencia: xhuni@yahoo.es 
UN HECHO PRETÉRITO: LA INSTAURACIÓN DE LAS ZONAS ECONÓMICAS ESPECIALES EN MÉXICO.

\section{RESUMEN}

El presente artículo, da cuenta del origen y cauce de las Zonas Económicas Especiales en México (ZEE), desde dos perspectivas: i) la norma constitucional y ii) la realidad de las propias regiones en donde se instalan; ambas representaron, en su momento, un alto valor para el impulso de las ZEE en las ocho entidades federativas: Veracruz, Guerrero, Chiapas, Oaxaca, Michoacán, Campeche, Tabasco y Yucatán.

La importancia de conocer los alcances de las ZEE es que estas se concibieron como eje de la estrategia gubernamental para el desarrollo económico y social de dichas regiones del país.

OBJETIVO: Dar cuenta sobre la instauración de las ZEE y su estatus durante el sexenio 20122018.

MATERIAL Y MÉTODO: La investigación se realizó empleando el método histórico, la teoría del crecimiento endógeno y la teoría de la localización con enfoque cualitativo, basándose en las fuentes de información secundarias (literatura especializada, diarios nacionales, revistas científicas, entre otras), a fin de identificar los alcances de esta política pública de desarrollo social como lo son las ZEE.

RESULTADOS: Se identificó que las ZEE son espacios territoriales con tratos preferenciales en toda una geografía nacional.

CONCLUSIONES: La puesta en marcha de las ZEE es una oportunidad para la economía y el desarrollo regional que mucho abona para el combate a la pobreza.

PALABRAS CLAVE: Economía regional. Crecimiento. Localización. Zonas Económicas Especiales.

\section{ABSTRACT}

This article gives an account of the origin and channel of the Special Economic Zones in Mexico (SEZ), from two perspectives: i) the constitutional norm and ii) the reality of the regions where they are installed; both represented, at their time, a high value for the promotion of SEZs in the eight states: Veracruz, Guerrero, Chiapas, Oaxaca, Michoacán, Campeche, Tabasco and Yucatán. 
UN HECHO PRETÉRITO: LA INSTAURACIÓN DE LAS ZONAS ECONÓMICAS ESPECIALES EN MÉXICO.

The importance of knowing the scope of the SEZs is that they were conceived as the axis of the governmental strategy for the economic and social development of these regions of the country.

OBJECTIVE: To report on the establishment of the SEZs and their status during the 20122018 sexennium.

MATERIAL AND METHOD: The research was carried out by using the historical method, the endogenous growth theory and the localization theory with a qualitative approach, based on secondary sources of information (specialized literature, national journals, scientific journals, among others), in order to identify the scope of this public policy of social development such as the SEZs.

RESULTS: It was identified that the SEZs are territorial spaces with preferential treatment throughout a national geography.

CONCLUSIONS: The implementation of the SEZs is an opportunity for the economy and regional development that helps a lot to the fight against poverty.

KEYWORDS: Regional economy. Growth. Location. Special Economic Zones.

\section{INTRODUCCIÓN}

En la actualidad, coexisten en el contexto global un sinfín de estrategias gubernamentales para lograr niveles de crecimiento que posibiliten a la base social tener mejores condiciones de vida y con ello, generar un dinámica progresiva y creciente en la economía nacional o local, hasta alcanzar ventajas comparativas, competitivas o absolutas como bien lo exponen en sus textos clásicos Adams Smith, con su libro "La riqueza de las naciones"; David Ricardo con On the principles of political economy and taxation; o Michel Porter con Ventaja competitiva: Creación y sostenimiento de un desempeño superior.

En efecto es así, ya que existen naciones que han impulsado políticas públicas de desarrollo o acciones institucionales basados en la economía del conocimiento para apuntalar una economía creciente en el contexto global; tales son los casos de China o Corea del Sur, que antes presentaban grandes rezagos de desarrollo y competitividad, quienes fijaron su 
UN HECHO PRETÉRITO: LA INSTAURACIÓN DE LAS ZONAS ECONÓMICAS ESPECIALES EN MÉXICO.

atención en dos cuestiones: a) constituir espacios especiales en sus geografías para darle un trato determinado (estímulos o exenciones fiscales), con el objeto de atraer inversiones (nacionales o extranjeras) y, b) invertir en Investigación y Desarrollo Experimental (lyDE) por encima del 1 o $2 \%$ de su Producto Interno Bruto (PIB).

Estos entornos han posibilitado que estos países sean naciones competitivas con un crecimiento promedio del $8 \%$ y una renta per cápita que se elevó 25 veces, incluso, son capaces de financiar proyectos tecnológicos en otros países. Contrario a sus similares que antes eran economías prósperas y estables como el caso de México, que hoy presenta una caída de su PIB por debajo de sus pares de la OCDE (2017). Por ello, los resultados de darle especial atención a las políticas públicas de desarrollo o políticas públicas basadas en la economía del conocimiento, llevaron a estas naciones a lograr ventajas competitivas y, de ese modo, tener las capacidades para insertarse como país en un proceso de globalización cada vez más abierto y complejo (Krugman, 1987 y 2000; Barro y Sala-i-Martin, 1995; Mankiw, 2002).

Las naciones que promueven las ZEE, han dado cuenta que esta política es una estrategia gubernamental de desarrollo de largo alcance, no sólo por los cimientos teóricos, técnicos y científicos que revisten los estudios para la localización de la región en la geografía nacional (North, 1972), sino también el valor agregado que se ha gestado en la economía local, regional, estatal o nacional mediante la formación y la capacitación del capital humano, tal como se postula desde la teoría del crecimiento endógeno. En efecto es así, teniendo presente a Barro y Sala-i-Martin (1995) y Temple (1999) quienes postulan que el crecimiento depende fundamentalmente de tres factores: capital físico, capital humano y capital cultural ${ }^{1}$ (cuando se hable de éste se refiere a conocimiento o progreso técnico). Lo que en consecuencia, hace afirmar que un nivel educativo creciente en combinación con una mayor capacitación del capital humano son variables centrales en el aumento de la productividad laboral como factor relevante para el desarrollo económico.

En ese sentido, es posible afirmar que las ZEE se explican muy bien desde la economía y, especialmente, por las teorías de desarrollo regional incorporando la variable territorial (Barro y Sala-i-Martin, 1995; Graisbord, 1988; Perroux, 1955; Garza, 1992; Aguilar, 1993; Martínez del Campo, 1985) o, en su caso, por la teoría de la localización (North, 1972; Kunkliski, 1972; Solow, 1956; Temple, 1999; Mankiw, 2002), mismas que resaltan la importancia de sumar

\footnotetext{
${ }^{1}$ De acuerdo con Bourdieu (1986) constituye el back de conocimientos que impulsa el desarrollo.
} 
UN HECHO PRETÉRITO: LA INSTAURACIÓN DE LAS ZONAS ECONÓMICAS ESPECIALES EN MÉXICO.

desarrollo económico con las condiciones del entorno local o espacio geográfico, así como el desarrollo económico con el desarrollo industrial.

Dados los retos de las ZEE desde una perspectiva regional (Solow, 1956; Temple, 1999; Mankiw, 2002; entre otros), la economía mexicana observa un crecimiento geográfico, donde las regiones que componen su territorio expresan cambios en su configuración. De ahí que las ZEE se erigen como áreas prioritarias para el desarrollo nacional, siendo el Estado con apego a su base fundacional, el eje articulador con la suma y participación del sector privado, social, productivo, empresarial y de las universidades, a través de un cúmulo de incentivos con miras a generar una agenda industrial sustentable con vertientes sectoriales y regionales.

\section{GÉNESIS DE LAS ZONAS ECONÓMICAS ESPECIALES (ZEE)}

La instauración de las Zonas Económicas Especiales (ZEE), constituyen hoy por hoy, para cualquier país un polo de desarrollo que agrega valor a la economía nacional si, y solo si, su impulso sea ordenado y sistematizado con apego a los postulados que asumen estudios de la economía regional y de la teoría de la localización, así como también tome para sí los dictados de la política pública (Bardach, 2001; Mèny y Thoenig, 1992; Aguilar, 1994).

De la información que se tiene memoria, se puede afirmar que la primera ZEE se creó en Gibraltar en 1704 y Singapur en 1819. Posterior a esta fecha, vinieron otras de gran importancia, cobrando vigencia aquella que se fundó en 1959 en Shannon, Irlanda, pero tuvo un especial impulso en 1965 con China (Shenzhen, Zhubai y Shantou) donde sus ZEE han sido exitosas, como también los casos de Bangladesh (Chittagong), Brasil (Manaos), Corea del Sur (Incheon y Mazan), Emiratos Árabes Unidos (Jebel Ali), Jordania (Aqaba), Letonia (Puerto de Ventspils), Malasia (Corredor Oriental), Marruecos (Tánger), Panamá (Colón), Polonia (Katowice) y Rusia (Alabuga, Lipetsk, Titanovaya Dolina, y Tolyatti, entre otras), como se observa en González García y Meza Lora (2009); Banco Mundial (2012); SHCP-AFDZEE (2017); y Candelas (2016).

Al respecto, señala Robles (2015, pp. 3-4), teniendo presente al Banco Mundial (2012), González García y Meza Lora (2009), así como Candelas (2016) que:

La dimensión internacional de las ZEE está caracterizada por ser una de las maneras más eficaces para atraer inversión extranjera en la práctica mundial; al tiempo, que contribuyen a la diversificación económica y fomentan la innovación científica y tecnológica (...) Las ZEE se definen como un área del territorio nacional delimitado por 
UN HECHO PRETÉRITO: LA INSTAURACIÓN DE LAS ZONAS ECONÓMICAS ESPECIALES EN MÉXICO.

el Estado, donde las empresas nacionales y/o extranjeras, están favorecidas por diferentes ventajas aduaneras, fiscales y administrativas.

Las ZEE se clasifican de acuerdo a su entorno y características de las regiones, pudiendo ser éstas: industriales, tecnológicas, turísticas y portuarias o, en su caso, una combinación en un solo espacio geográfico como bien lo refiere Robles (2015, p. 4) tomando en consideración lo expuesto en González García y Meza Lora (2009) y Banco Mundial (2012).

\section{LAS ZONAS ECONÓMICAS ESPECIALES EN MÉXICO}

Las ZEE es un ejercicio único e innovador en la realidad nacional para el gobierno federal del sexenio 2012-2018, toda vez que se vislumbró como una estrategia de alto valor para la construcción de una economía regional robusta y creciente para alcanzar niveles de bienestar social, incluso en una experiencia sin parangón en materia de política de desarrollo en México; no así en el contexto global toda vez que entre 2005 y 2015 ya existían un poco más de 3 mil 36 en 120 países en sus diferentes modalidades y acepciones: Zonas de Libre Comercio, Zonas Francas, Zonas Procesadoras de Exportaciones, Zonas Económicas Libres, Zonas de Desarrollo Económico y Tecnológico, entre otras similares (González García y Meza Lora, 2009; Banco Mundial, 2012; SHCP-AFDZEE, 2017).

Al analizar los casos de éxito y fracaso a nivel global de las ZEE, así como también las mejores prácticas internacionales, es posible afirmar que la instauración de éstas en la realidad mexicana es concebida con un enfoque integral para garantizar que logren sus objetivos de desarrollo económico y social, diversificación productiva, ascenso industrial y atracción de inversiones. En su impulso y establecimiento en las entidades federativas del sur-sureste en donde existen altos y muy altos rezagos con el objeto de abatir la pobreza mediante una política económica que genere riqueza en dichas regiones y, en consecuencia, estimular el potencial productivo y logístico de éstas con miras a crear empleos bien remunerados y oportunidades productivas que permitan a la base social superar sus condiciones de vida (SHCP-AFDZEE, 2017). Detonar el potencial productivo de las entidades federativas en donde se establecen las ZEE, es de gran relevancia identificar las barreras estructurales características de las regiones (Padilla y De Sicilia, 2018).

El documento oficial de las ZEE en México, señala:

"Hay una parte del país que compite y gana en la economía global, con índices crecientes de ingreso, desarrollo y bienestar. Pero hay otra que se ha quedado 
UN HECHO PRETÉRITO: LA INSTAURACIÓN DE LAS ZONAS ECONÓMICAS ESPECIALES EN MÉXICO.

rezagada; que no ha podido aprovechar su enorme potencial productivo y que sufre carencias sociales inaceptables en pleno siglo XXI (...) Las Zonas Económicas Especiales son la respuesta del Estado Mexicano para cerrar las brechas de desigualdad regional; para impulsar un desarrollo equilibrado, sostenido, sustentable e incluyente. Son la estrategia para crear nuevos polos industriales en las entidades con mayores rezagos, a partir de una política pública innovadora, moderna y progresista, enfocada en atraer inversiones, elevar la productividad y generar empleos bien remunerados" (SHCP-AFDZEE, 2017, p. 1).

Así también, este documento refiere que las ZEE en el contexto mundial suma un poco más de 70 millones de empleos, atraen $21 \%$ de la Inversión Extranjera Directa (IED) y producen $41 \%$ de las exportaciones globales. En efecto, esta experiencia global y las condiciones socioeconómicas de México, son hoy por hoy razones que llevaron a concretar acciones e impulsar trabajos desde diferentes frentes (Congreso de la Unión y sectores empresarialesproductivos) para el establecimiento de las primeras ZEE en Puerto Chiapas (Chiapas), Coatzacoalcos (Veracruz), y Lázaro Cárdenas-La Unión (Michoacán y Guerrero), y después Oaxaca, Yucatán, Campeche aprovechando la geografía específica de comunicación que éstas tienen con el Océano Pacifico y el Golfo de México y las vocaciones productivas que emergen en cada uno de estas localidades (Candelas, 2016), lo que en consecuencia hacen que se erijan como puertos en posiciones geoestratégicas con ventajas comparativas y/o ventajas absolutas en palabras de Adams Smith en su libro La riqueza de las naciones; y David Ricardo con The principles of political economy and taxation.

En este mismo tenor, el documento oficial de las ZEE, señala:

“(...) habrá que añadir los incentivos locales adicionales que están en preparación para cada ZEE, relacionados con gravámenes de traslado de dominio, nómina, predial y, para las áreas de influencia, impuesto al hospedaje. Las ZEE incluirán otro tipo de estímulos, no fiscales, vinculados con financiamiento, capacitación, certificación, fondos para emprendedores, proveeduría y empresas sociales, entre otros. Además de incluir, por supuesto, el valor de un esquema regulatorio y ecosistema de servicios único para los inversionistas y las empresas, alrededor del concepto de Ventanilla Única" (SHCP-AFDZEE, 2017, p. 3). 
Original

UN HECHO PRETÉRITO: LA INSTAURACIÓN DE LAS ZONAS ECONÓMICAS ESPECIALES EN MÉXICO.

\section{MARCO INSTITUCIONAL Y JURÍDICO DE LAS ZONAS ECONÓMICAS ESPECIALES EN MÉXICO}

Entre las líneas del documento, por un México en paz con justicia y desarrollo, de fecha 24 de noviembre de 2014 en su página 9, el Gobierno Federal señala "(..) La justicia que queremos va más allá del ámbito legal. Incluye también la reducción de la pobreza, la marginación y la desigualdad que padecen los estados del Sur del país”. De ahí, se expone que el país camina en dos vías: i) que se alinea con el proceso global con una dinámica creciente y ii) que no logra aprovechar lo que emana del proceso de globalización y, sí, por el contrario, presenta una economía reducida con bajos índices de ingreso, desarrollo y bienestar.

Posterior a este esfuerzo conjunto, el 1 de junio de 2016 se publica en el DOF, el Decreto por el que se expide la Ley Federal de Zonas Económicas Especiales (LFZEE) y, como consecuencia, se expide el Reglamento y el Decreto por el que se crea la Autoridad Federal para el Desarrollo de las Zonas Económicas Especiales (30 de junio). Este primer ordenamiento dio vigencia por primera vez una política pública de desarrollo social de largo alcance, no sólo por el significado del mismo, los actores que involucra y las mejoras que introduce en las regiones donde emerge, sino también por el impulso que agrega a la dinámica local en materia laboral, productiva y educativa (Robles, 2017).

En adición a lo anterior, es pertinente retomar lo dicho por el Gobierno Federal $(2014,11)$ cuando afirma que el esfuerzo es dar a estas ZEE “(...) infraestructura moderna, condiciones de seguridad, financiamiento preferencial de la Banca de Desarrollo, facilidades adicionales para el comercio exterior, así como importantes descuentos en los impuestos y contribuciones al Instituto Mexicano del Seguro Social y al INFONAVIT". Incluso refiere que "(...) la experiencia internacional confirma que las zonas económicas especiales son eficaces para atraer inversión nacional y extranjera, contratar servicios locales y aumentar la competitividad de las empresas".

Sobre este tenor, afirma Robles (2015, p. 8) que el impulso de las ZEE necesitará no sólo de la cooperación de los agentes privados y de las instituciones del sector público (CONACYT, IMSS, INFONAVIT, SCT, entre otros), sino que debe diseñarse un andamiaje legal ad hoc que estimule la consolidación de esta estrategia gubernamental. Así también, para que las ZEE operen con gran rigor y poder deben perennemente "(...) lograr una transición hacia la desgravación y liberación arancelaria en relación con el comercio de la región; además de la exención de pagos de aprovechamiento a empresas que vayan a formar parte de la zona en 
UN HECHO PRETÉRITO: LA INSTAURACIÓN DE LAS ZONAS ECONÓMICAS ESPECIALES EN MÉXICO.

cuestión". Por su parte, Candelas (2016) refiere que de estas acciones derivarían una serie de disposiciones generales como son la delimitación geográfica de la ZEE, los inmuebles del dominio público federal, la delimitación del área de Influencia, los beneficios e incentivos fiscales.

Con la puesta en marcha de la Ley de ZEE, se derivaron múltiples acciones institucionales, dando entre éstas, que tres meses después (29 de septiembre) se estableciera lo que ya se conocía por los sectores productivos, empresariales, universidades, sociedad y gobierno. La Declaratoria de Creación de las ZEE: Puerto Chiapas, Chiapas; Coatzacoalcos, Veracruz; y Lázaro Cárdenas, La Unión, compartida entre Michoacán y Guerrero; acto seguido, se decreta el 19 de diciembre de 2017, las ZEE del Puerto de Salina Cruz, Oaxaca y Progreso, Yucatán; y el 18 de abril de 2018 se instauran las ZEE de Paraíso, Tabasco y Champotón, Campeche. Los únicos ochos en la realidad nacional, sin que éstas se propagaran en toda la geografía nacional por la cancelación de las mismas en el sexenio actual (2018-2024)².

Este impulso del Gobierno de formar a estos puertos como parte integral de las ZEE, tiene su razón de ser si se tiene presente el mensaje "Por un México en paz con justicia y desarrollo", cuando el Gobierno Federal afirma que por las condiciones sociales (de pobreza y marginación) en la región sur y su ínfimo desarrollo frente a sus similares, motiva "(...) por primera vez en nuestra historia, propongo que se establezcan tres zonas económicas especiales en la región más atrasada del país. (...) Éstas serán: el Corredor Industrial Interoceánico, en el Istmo de Tehuantepec, que conectará al Pacífico con el Golfo de México; la segunda, en Puerto Chiapas; y la tercera, en los municipios colindantes al Puerto de Lázaro Cárdenas, tanto de Michoacán, como de Guerrero".

Para Ojeda (2011, p. 21) ésta estrategia gubernamental de promover la región Sur-Sureste como ZEE tiene un alto valor, toda vez que "los puertos son vistos no sólo como una unidad "microeconómica" o centro de negocios, sino ubicados en una ciudad y puerto, pertenecientes a una región económica que tiene potencialidades, recursos, empresas y agentes económicos y sociales en pugna por el excedente económico".

\footnotetext{
2 Diversos diarios de circulación nacional dieron cuenta lo señalado por el Presidente López Obrador al anunciar la desaparición de las Zonas Económicas Especiales por las razones de que éstas "Eran supuestamente para ayudar, pero nunca hicieron nada por ayudar. Hicieron negocios, compraron terrenos y derrocharon recursos no se benefició en nada". Así también, la oficina de Presidencia aclaró que desde el Gobierno no se seguirá apoyando el proyecto de ZEE y se apostará en su lugar por "proyectos de desarrollo" ver diario El Financiero de fecha 25/04/2019: https://www.elfinanciero.com.mx/nacional/lopez-obrador-anuncia-la-desaparicion-de-las-zonaseconomicas-especiales.
} 
UN HECHO PRETÉRITO: LA INSTAURACIÓN DE LAS ZONAS ECONÓMICAS ESPECIALES EN MÉXICO.

Para la operación de las ZEE, es la Autoridad Federal para el Desarrollo de las Zonas Económicas Especiales- AFDZEE- (Órgano Administrativo Desconcentrado de la Secretaría de Hacienda y Crédito Público) la que se erige como la instancia facultada para emitir las disposiciones que regulen el otorgamiento de permisos, asignaciones y autorizaciones a los Administradores Integrales y a los inversionistas, así como para establecer requisitos, procedimientos y criterios de evaluación que deberán observarse, a través de concursos públicos y, tratándose de bienes inmuebles de la Federación, de concesiones, que habiliten a sociedades mercantiles mexicanas para construir, desarrollar, administrar y mantener una Zona o una sección de la misma (DOF, 29/09/2017).

Así también, la AFDZEE otorga concesiones y otros derechos respecto de los bienes del dominio público de la Federación que le hubieren sido destinados, de acuerdo con la Ley Orgánica de la Administración Pública Federal y la Ley General de Bienes Nacionales, en el carácter de administradora de inmuebles, únicamente respecto de aquellos que se requieran para el establecimiento y operación de las ZEE.

Es menester señalar que las acciones y pesos de la AFDZEE es afín a las entidades federativas en donde emergen las ZEE pues aun con su autonomía y su carácter federal, concilia intereses locales, regionales, estatales y federales para ser coadyuvantes en la diseño e implementación de tareas en el contexto de esta política pública de desarrollo (SHCPAFDZEE, 2017).

\section{LEY FEDERAL DE LAS ZONAS ECONÓMICAS ESPECIALES}

Con el Decreto de Creación de las ZEE en México, se da un viraje sin parangón en la política pública de desarrollo social de antaño en el sentido de que esta es una experiencia probada en el contexto global en donde existen 3 mil 36 ZEE en 120 países en sus diferentes modalidades y acepciones (Banco Mundial, 2012; González García y Meza Lora, 2009) y, no sólo eso, sino también porque en su impulso suma diversos agentes, sean: institucionales, sociales, empresariales, productivos, económicos y académicos (SHCP-AFDZEE, 2017).

En efecto la Ley de las ZEE es innovadora al proponer en su artículo $1^{\circ}$ :

“(...) impulsar el crecimiento económico sostenible que, entre otros fines, reduzca la pobreza, permita la provisión de servicios básicos y expanda las oportunidades para vidas saludables y productivas, en las regiones del país que tengan mayores rezagos 
UN HECHO PRETÉRITO: LA INSTAURACIÓN DE LAS ZONAS ECONÓMICAS ESPECIALES EN MÉXICO.

en desarrollo social, a través del fomento de la inversión, la productividad, la competitividad, el empleo y una mejor distribución del ingreso entre la población".

Asimismo, identifica a las ZEE en su artículo 3, como:

"Áreas prioritarias del desarrollo nacional; el Estado promoverá las condiciones e incentivos para que, con la participación del sector privado y social, se contribuya al desarrollo económico y social de las regiones en las que se ubiquen, a través de una política industrial sustentable con vertientes sectoriales y regionales".

Sumado a este, la Ley establece que "Los beneficios e incentivos que se otorguen deberán fomentar la generación de empleos permanentes, el ascenso industrial, el crecimiento de la productividad del trabajo, e inversiones productivas que impulsen el desarrollo económico de la zona y su área de Influencia".

Para la definición de una ZEE, la AFDZEE emite la declaratoria con base al artículo 8 de la referida Ley de Creación:

a) La delimitación geográfica precisa de la zona (...); b) La delimitación geográfica del área de influencia (...); c) Los motivos que justifican la declaratoria; d) Las facilidades administrativas y los incentivos fiscales(...); e) El plazo dentro del cual deberá celebrarse el Convenio de Coordinación; f) La fecha a partir de la cual iniciará operaciones la zona, y; g) Los demás requisitos que establezca el Reglamento de esta ley.

Es pertinente afirmar, que mediante órgano colegiado se gesta el Programa de Desarrollo $(P d D)$ de cada ZEE y su revisión será cada cinco años para su posible ajuste ${ }^{3}$.

Para tal efecto, señalan Candelas (2016) y Padilla y De Sicilia (2018) la propia Ley otorga incentivos y facilidades para las empresas que se establezcan en las ZEE, todo ello para propiciar un impulso integral de las regiones y, así, la inversión sea de largo aliento que trastoque la infraestructura física y social de las localidades y comunidades, incluso que incida grandemente en el reglón en materia educativa.

A este respeto, la Ley en su artículo 13 establece:

\footnotetext{
${ }^{3}$ Artículo 12 de la LFZEE y artículo 58 del RLFZEE. El subrayado es mío (objeto del presente trabajo de tesis). 
UN HECHO PRETÉRITO: LA INSTAURACIÓN DE LAS ZONAS ECONÓMICAS ESPECIALES EN MÉXICO.

"Los beneficios serán temporales y, en su caso, el monto de la desgravación o descuentos de las contribuciones se otorgarán de manera decreciente en el tiempo $(\ldots)$

Referente al Impuesto al Valor Agregado, menciona:

“(...) los beneficios fiscales tendrán como propósito desgravar los bienes que se introduzcan a dichas zonas, así como los servicios que se aprovechen en las mismas, cuando esas actividades se lleven a cabo por empresas residentes en México, actividades que estarán afectas a la tasa de $0 \%$. (...)".

Sobre el Impuesto Sobre la Renta, expone:

“(...) los beneficios fiscales deberán promover la inversión productiva, la formación de capital humano y la capacitación de los trabajadores, de forma que se impulse la generación de empleo de alto valor agregado y la elevación de las remuneraciones de los trabajadores empleados en las zonas (...) estos beneficios deberán tener como mínimo una duración de ocho años. Durante su vigencia no podrán modificarse dichos beneficios en perjuicio de los contribuyentes respectivos, sin perjuicio de su condición decreciente".

Sobre este tenor, el documento del Banco Mundial (2012, p. 3) hace hincapié de las bondades que derivan de impulsar las ZEE en cualquier país:

“(...) la mayoría de las zonas económicas ofrecen a los inversionistas orientados a la exportación tres ventajas principales en relación con el entorno de la inversión interna: 1) un entorno aduanero especial $(\ldots) ; 2$ ) la infraestructura (como la renta de propiedades, armazón de las fábricas y servicios básicos) (...); y 3 ) incentivos fiscales $(\ldots) "$

El mandato de esta Ley de las ZEE está compuesto por 50 artículos y cuatro transitorios, que pasa por quien encabeza la AFDZEE, las atribuciones, la estructura organizativa, la participación de los actores, el alcance del mismo, incluso acciones de transparencia, rendición de cuenta y sanciones, lo que en consecuencia la hace una política pública estructurada (Bardach, 2001; Mêny y Thoenig, 1992). 
UN HECHO PRETÉRITO: LA INSTAURACIÓN DE LAS ZONAS ECONÓMICAS ESPECIALES EN MÉXICO.

\section{CAUCE ACTUAL DE LAS ZONAS ECONÓMICAS ESPECIALES EN MÉXICO}

Este esfuerzo primigenio que llevaría a la creación e impulso de las ZEE tiene su origen el 27 de noviembre de 2014 cuando el Gobierno Federal anunció la intención por emprender su instalación como parte de una nueva política de desarrollo social y, que al poco andar esta estrategia gubernamental, el Congreso de la Unión a través de Cámara de Baja la hizo suya y la sometió a consideración del pleno para aprobar la iniciativa con proyecto de decreto y el 14 de diciembre de 2015, aprobó el dictamen que expide la Ley Federal de ZEE, a su vez la Cámara Alta hizo lo propio cuatro meses después (SHCP-AFDZEE, 2017): éstas ZEE tienen su localización en zonas portuarias.

Con el Decreto de Creación de las ZEE, un sinfín de ajustes se originan en la estructura institucional, constitucional y presupuestal en el espectro de la Federación y, en consecuencia, en las finanzas de las entidades federativas en donde se asienta esta estrategia gubernamental.

Este hecho, significó para la realidad nacional una acción pública de gran trascendencia, toda vez que el Gobierno Federal instrumenta un numeral de acciones, trabajos y proyectos de desarrollo que devienen del establecimiento de las ZEE, aunque ésta por sí misma no podrá subsanar los grandes males estructurales que subyacen en las regiones especiales en donde la pobreza es extrema y de marginación es alta. Las ZEE deben ir acompañadas de acciones públicas vinculadas a la economía regional y de políticas públicas transversales en lo social y en lo educativo.

Su puesta en marcha no corrige per se estas condiciones de podredumbre, sino se concibe como una política pública de Estado más allá de ideologías y posiciones políticas (Bardach, 2001; Mêny y Thoenig, 1992). Su ejecución no corrige o matiza este problema (pobreza extrema y alta marginación) que lesiona la condición de la base social y limita la dinámica de un sociedad que está ávida de oportunidades y sí, por el contrario, trastoca la construcción del capital social (Putnam, 1993; Coleman, 1990) en el entramado nacional que posibilite a las comunidades, localidades, pueblos o regiones alcanzar los beneficios derivados de la generación de riqueza (empleo remunerado) y de los frutos que devienen del esfuerzo productivo nacional (bien común) (Martínez, 2017).

Con la creación de las ZEE se fijó que éstas se erigieran en polo de desarrollo e inversión en las regiones en donde se circunscriben y, en consecuencia, representen, sin duda alguna, en una coyuntura para impulsar el desarrollo económico local. Las acciones derivadas de esta 
Original

UN HECHO PRETÉRITO: LA INSTAURACIÓN DE LAS ZONAS ECONÓMICAS ESPECIALES EN MÉXICO.

estrategia gubernamental permitirían aprovechar las ventajas comparativas y/o absolutas de estas geografías (Candelas, 2016). Verbi gratia: Las construcciones de obras de infraestructura en la ZEE de Salina Cruz señalan Padilla y De Sicilia (2018), están llamadas a potencializar la economía en el contexto local, regional y estatal, al tiempo, que introduciría nuevas rutas de comercio intercontinental. En efecto, según Torres (2018) al afirmar que con el desarrollo del proyecto Corredor Industrial Interoceánico, se impulsa en el Istmo de Tehuantepec, en especial a Salina Cruz como polo de desarrollo e inversión que puede beneficiar a 49 municipios de Oaxaca (e incluso a 31 municipios de Veracruz).

Con el Corredor Industrial Interoceánico se visualiza en activar la economía del Sur-Sureste, toda vez que los polos que conecta esta vía de comunicación presentan grandes rezagos socioeconómicos, que propicia el quiebre de la base social al extremo de estar en constante riesgo su vida por la limitada infraestructura- seguridad social, seguridad pública, seguridad ciudadana, (PED, 2010-2016 y 2016-2022).

Es menester señalar que, el Corredor Industrial Interoceánico en el Istmo de Tehuantepec (también llamado Corredor de Transporte Interoceánico en el Gobierno de 1994-2000) no es nuevo en la realidad nacional, puesto que este proyecto- como bien lo refiere Torres (2018, pp. 135-136)- formó parte del...

"Programa Integral de Desarrollo Económico para el Istmo de Tehuantepec para que la región se incorporara al comercio mundial de bienes y servicios, programa que por su escala en materia de infraestructura y financiera se le conoció como Megaproyecto del Istmo, el cual se integró 64 proyectos distribuidos en once paquetes estimados como detonadores para la región por gobiernos federales, así como de Oaxaca y Veracruz (...). Este corredor de transporte interoceánico, representó una acción prioritaria para desarrollar aún más la industria del petróleo en México, lo que implicaba la rehabilitación del Ferrocarril del istmo y la ampliación y mejora de infraestructura portuaria en Coatzacoalcos y Salina Cruz. Se contemplaba una inversión de 19 mil millones de pesos para generar, en un plazo máximo de cinco años, 11,000 empleos directos (...)"

Se debe afirmar que, si bien se observaron avances de las ZEE desde su instauración y al término del sexenio 2012-2018, hoy por hoy es un hecho pretérito; aunque a decir por Robles (2017) hay pocos elementos concretos para una evaluación objetiva sobre la viabilidad de ésta como política social de desarrollo. 
UN HECHO PRETÉRITO: LA INSTAURACIÓN DE LAS ZONAS ECONÓMICAS ESPECIALES EN MÉXICO.

\section{CONCLUSIONES}

La puesta en marcha de las ZEE es una oportunidad para la economía y el desarrollo regional, que mucho abona para el combate a la pobreza a través del impuso y dinámica de los sectores productivos para, de ese modo, incidir en la productividad laboral.

No obstante, hay que afirmar que no todas las ZEE que se han implementado en 120 países han sido exitosas, por lo que de estos debe haber aprendizajes que se vuelven referentes para cualquier país que inicie políticas públicas de desarrollo social, basadas en la instauración de ZEE.

Es de reconocer que toda inversión que se instale en la ZEE gozan de un tratamiento especial, debido a que llegan con altas ventajas en el mercado y, en consecuencia, se minimizan sus márgenes de riesgo en todas las áreas de su competencia.

Algo innegable que se observa en las ZEE es, que el proceso de globalización mucho ayuda a los países que adoptan esta política pública, no sólo por la interacción dinámica de los agentes del mercado en su entorno, sino también las ventajas que guardan estos países frente a sus pares.

La identificación de las vocaciones productivas de las regiones es prioritaria para la instauración de las ZEE, al tiempo, que éstas deben ir acompañada de una oferta educativa ad hoc que abone en la productividad empresarial y laboral para, de ese modo, garantizar la permanencia y pertinencia de los sectores productivos.

En el estudio de las ZEE no hay mejor marco teórico para su tratamiento que la teoría del crecimiento endógeno o la teoría de la localización, en donde el primero resalta el entorno local, el conocimiento y el capital humano; mientras que el segundo tiene a bien identificar la geografía o ubicación de la empresa o unidad económica de producción para incidir en los costos de traslado.

Para el caso de México, si bien es cierto, lo que se apunta en el Plan Nacional de Desarrollo 2013-2018, en el capítulo referido a México Próspero, en donde se reconoce que dadas las condiciones socioeconómicas de las naciones emergentes, se debe priorizar la industrialización acelerada, porque logrando aumentar dramáticamente la productividad, mejorarán los salarios, los beneficios y propiciarán la indispensable acumulación de capital que requiere la industrialización; de ahí, el impulso de un sinfín de políticas públicas, sobre todo, la política de desarrollo social como lo es la instauración de las ZEE. 
UN HECHO PRETÉRITO: LA INSTAURACIÓN DE LAS ZONAS ECONÓMICAS ESPECIALES EN MÉXICO.

\section{REFERENCIAS BIBLIOGRÁFICAS}

Aguilar, I. (1993). Desconcentración Industrial en México. México: Colegio de México.

Aguilar, L. (1994). Antologías de política pública: El estudio de las políticas públicas. México: Porrúa.

Banco Mundial (2012). Desarrollando el Potencial Exportador de América Central. Infraestructura para Desarrollar las Exportaciones: Zonas Económicas Especiales, Innovación y Sistemas de Calidad. Departamento de Financiamiento y Desarrollo del Sector Privado, Unidad Gerencial del País América Central, Región de América y el Caribe.83927 4.

Bardach, E. (2001). Los ocho pasos para el análisis de políticas pública. México: CIDE.

Barro, R. y Sala-i-Martin, X. (1995). Economic Growth. New York: McGraw-Hill.

Candelas, R. (2016). Zonas Económicas Especiales en México. Marco General de Referencia para su Instalación, Desarrollo y Viabilidad Presupuestal. Documento de Trabajo número (224). Agosto. México: Centro de Estudios Sociales y de Opinión Pública (CESOP). Cámara de Diputados, México.

Coleman, J. (1990). Foundations of Social Theory. USA: Harvard University Press.

Douglass. N. (1972). La teoría de la localización y el crecimiento económico regional. Chile: CEPAL.

Ejecutivo Federal Secretaría de Gobernación. (2016). Diario Oficial de la Federación (DOF).

Garza, G. (1992). Desconcentración, tecnológica y localización industrial. México: Colegio de México.

González, J. y Meza, J. (2009). Shenzhen, Zona Económica Especial: Bisagra de la apertura económica y el desarrollo regional chino. Problemas del Desarrollo. Revista Latinoamericana de Economía, 40(156), México: IIEc- UNAM.

Graisbord, B. (1988). Los insumos teóricos de una cuasiteoría: el concepto de polo de crecimiento una vez más. México: Universidad de Baja California.

Krugman, P., Fujita, M. y Venables, A. (2001). The Spatial Economy. USA: MIT. 
UN HECHO PRETÉRITO: LA INSTAURACIÓN DE LAS ZONAS ECONÓMICAS ESPECIALES EN MÉXICO.

Krugman, P. (1987). "Is Free Trade Passe?" USA: American Economic Association. Journal of Economic Perspectives, 1(2), 131-144.

Kuklinski, A. (1966). Teoría de los polos de desarrollo. México: Siglo XXI.

Mankiw, G. (2002). Principios de Economía, Madrid: McGraw-Hill.

Martínez del Campo, M. (1971). Desarrollo industrial en México. México: Colegio de México.

Mèny, I. y Thoenig, J. (1992). Las Políticas Públicas. España: Ariel.

OCDE (2017). Panorama de la educación en Nota País: México. París: OCDE.

Ojeda, J. (2011). Los puertos mexicanos en el siglo XXI: situación y debate (1991-2012). Ciencia y Mar, 15(45), México: UMAR.

Padilla, L. y De Sicilia, R. (2018). El Puerto de Salina Cruz: zona económica especial, futuro incierto, Desigualdad Regional, Pobreza y Migración. México: UNAM y Asociación Mexicana de Ciencias para el Desarrollo Regional, A. C.

Perroux, F. (1955). Note sur la notion de pole de croissance? Economie Appliquée, (307320).

Porter, M. (1996). Ventaja competitiva: creación y sostenimiento de un desempeño superior. México: Compañía Editorial Continental.

Putnam, R. (1993). The Prosperous Community. Social Capital and Public Life. The American Prospect, 4(13), 35-42.

Ricardo, D. (1817). On the principles of political economy and taxation. London: John Murray.

Robles, B. (2015). Ponencia Oaxaca: un modelo ZEE con inclusión social. Zona Económica Especial Istmo de Tehuantepec. Oaxaca de Juárez, Oaxaca. Agosto.

Robles, B. (2017). Ponencia Ciencia, Tecnología e Innovación. Estrategias para el Desarrollo Regional (Caso Salina Cruz, Oaxaca). España: Universidad Alcalá de Henares. Noviembre.

Secretaría de Hacienda y Crédito Público-Autoridad Federal para el Desarrollo de las Zonas Económicas Especiales (SHCP-AFDZEE) (2017). Las Zonas Económicas Especiales. 
UN HECHO PRETÉRITO: LA INSTAURACIÓN DE LAS ZONAS ECONÓMICAS ESPECIALES EN MÉXICO.

El gran proyecto de nación. Recuperado el 25 de diciembre de 2017 de https://www.gob.mx/se/articulos/las-zonas-economicas-especiales-de-mexico.

Smith, A. (2011). La riqueza de las naciones. España: Alianza Editorial.

Solow R. (1956). A Contribution to the Theory of Economic Growth. USA: The Quarterly Journal of Economics, 70(1), 65-94.

Temple, J. (1999). The New Growth Evidence. USA: American Economic Association. Journal of Economic Literature, 37(1), 112-156.

Torres, J. (2017). El corredor del Istmo de Tehuantepec: de los proyectos fallidos a las nuevas posibilidades para su desarrollo, Espacio Público, 20(48). Recuperado de http://www.redalyc.org/articulo.oa?id=67652755007 